archives

of thermodynamics

Vol. 38(2017), No. 3, 135-148

DOI: $10.1515 /$ aoter-2017-0020

\title{
Selected studies of flow maldistribution in a minichannel plate heat exchanger
}

\author{
PAWEE DĄBROWSKI ${ }^{*}$ \\ MICHAE KLUGMANN \\ DARIUSZ MIKIELEWICZ
}

Gdańsk University of Technology, Faculty of Mechanical Engineering, Department of Energy and Industrial Apparatus, Narutowicza 11/12, 80-233 Gdańsk, Poland

\begin{abstract}
Analysis of the state of-the-art in research of minichannel heat exchangers, especially on the topic of flow maldistribution in multiple channels, has been accomplished. Studies on minichannel plate heat exchanger with 51 parallel minichannels with four hydraulic diameters, i.e., $461 \mu \mathrm{m}$, $574 \mu \mathrm{m}, 667 \mu \mathrm{m}$, and $750 \mu \mathrm{m}$ have been presented. Flow at the instance of filling the microchannel with water at low flow rates has been visualized. The pressure drop characteristics for single minichannel plate have been presented along with the channels blockage, which occurred in several cases. The impact of the mass flow rate and channels' cross-section dimensions on the flow maldistribution were illustrated.
\end{abstract}

Keywords: Pressure drop; Minichannel; Plate; Heat exchanger; Flow maldistribution; Channel blockage

\section{Nomenclature}

$$
\begin{aligned}
& \text { A - surface area, } \mathrm{m}^{2} \\
& D \quad \text { - intake conduit diamater, } \mathrm{m} \\
& D_{h} \quad-\quad \text { hydraulic diamater, m } \\
& f \quad-\quad \text { average friction coefficient for intake conduit flow } \\
& h-\text { convective heat transfer coefficient, } \mathrm{W} / \mathrm{m}^{2} \mathrm{~K}
\end{aligned}
$$

\footnotetext{
${ }^{*}$ Corresponding Author. Email pawel.dabrowski@pg.edu.pl
} 


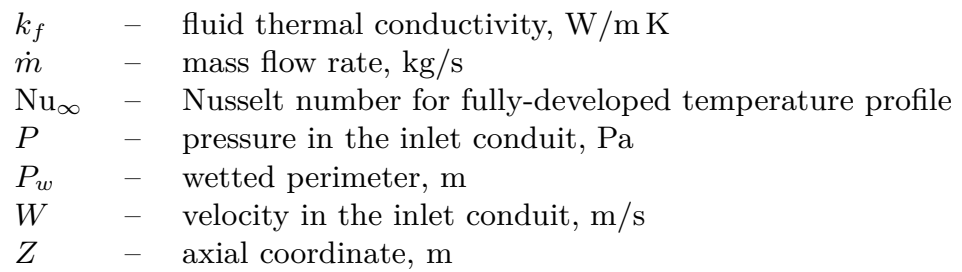

Greek symbols

$\beta-\quad$ average velocity ratio in the intake conduit

$\Delta P \quad-$ pressure drop, $\mathrm{Pa}$

$\rho \quad-\quad$ fluid density, $\mathrm{kg} / \mathrm{m}^{3}$

\section{Introduction}

All technology sectors are endeavoring to miniaturization with simultaneous improvement of the performance of considered appliances. That causes the increase of heat flux which is necessary to be dissipated from the surface, so the cooling systems have also to be improved. Hence, heat exchangers that are inherently an integral part of cooling systems are undergoing modifications. Well-known conventional or even compact heat exchangers are insufficient in many cases. Poor thermal management is a main drawback on the way of further miniaturization. Hence, there is a need to focus on modern designs of heat exchangers and to intensify the heat transfer.

Tuckerman and Pease [1] clearly demonstrated, about four decades ago, that convective heat transfer coefficient directly depends on the hydraulic diameter of the channel, which in minichannels is featuring the laminar character. Hence, for the constant value of the Nusselt number, $\mathrm{Nu}_{\infty}$, the product of heat transfer coefficient and hydraulic diameter is constant [2]

$$
h=\frac{k_{f} \mathrm{Nu}_{\infty}}{D_{h}} .
$$

As can be seen from Eq. (1) the smaller the hydraulic diameter, the higher is the convective heat transfer coefficient. That is also accompanied by a significant elevation of pressure losses in the exchanger. The latter conclusion introduced new generation of heat exchangers, i.e., minichannel heat exchangers, where the realized flow is predominantly laminar. Microand minichannels are different from the conventional channels in terms of channel hydraulic diameters. Ranges of hydraulic diameters proposed in [3]

$$
D_{h}=\frac{4 A}{P_{w}},
$$


are as follows: $D_{h}>6 \mathrm{~mm}$ for macrochannels, $1 \mathrm{~mm}<D_{h}<6 \mathrm{~mm}$ for minichannels, $0.1 \mathrm{~mm}<D_{h}<1 \mathrm{~mm}$ for mesochannels and $1 \mu \mathrm{m}$ $<D_{h}<100 \mathrm{~mm}$ for microchannels. Different classification was postulated in [4], i.e., channels can be defined as: conventional when $D_{h}>3 \mathrm{~mm}$, mini when $0.2 \mathrm{~mm}<D_{h}<3 \mathrm{~mm}$ and micro when $10 \mu \mathrm{m}<D_{h}<200 \mu \mathrm{m}$.

Mini- or microchannel heat exchangers are widely used in many industries, i.e., power industry (water cooled turbine blades, rocket nozzle cooling, fusion reactor blanket cooling, domestic micro-combined heat and power) [5-9], information technology industry (computer data centers) $[10,11]$, avionics industry (avionics cooling) [12], space industry (cooling of satellite electronics) [13], solar industry (solar photovoltaic panels) [14], automotive industry (cooling of hybrid vehicle power electronics) [15], chemical and biological industry [16,17], refrigeration industry (microfin tubes in residential cooling) [4] or cryogenic industry (heat exchangers for hydrogen storage systems) [18]. Kandlikar [19] reported that microchannels may provide a heat flux dissipation ratio up to $10^{3} \mathrm{~W} / \mathrm{cm}^{2}$.

Small diameter of channels causes a low mass flux of fluid that is able to flow through it and a moderate heat flux that can be dissipated from the cooled surface as a result. That is a reason for application of many parallel minichannels with common inlet and outlet manifold in minichannel heat exchangers. But this kind of construction causes a flow maldistribution. According to Mueller and Chiou [20], prefix 'mal' means defective or bad, so if a comparison is made to a uniform distribution, then 'maldistribution' means unequal amount of fluid or unequal flow velocity in each channel. In fact, there are two kinds of maldistribution connected with fabrication conditions: gross maldistribution and passage-to-passage maldistribution [21]. The first one is associated with mechanical design, mainly improper header configuration and the second one is caused by various manufacturing tolerances. But flow maldistribution can also appear due to heat transfer process, two-phase flows and fouling or corrosion [20].

Very significant aspect in heat exchangers designing is to choose proper inlet and outlet manifold configuration. Two main structures of manifolds can be distinguished, namely consecutive and bifurcation [22]. They are shown in Fig. 1 [23]. In consecutive manifolds the main fluid stream is divided continuously into channels as it reaches them. This structure is very common due to their simplicity and lower pressure drop comparing to bifurcation type. However, consecutive manifold is susceptible to flow maldistribution. Bifurcation structure is inspired by the nature and can be 


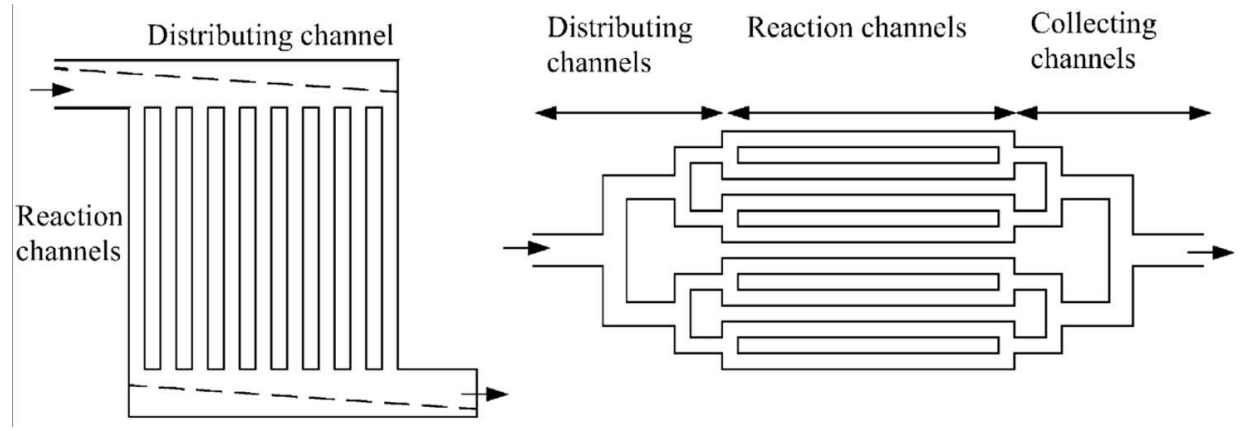

Figure 1: Schematic for consecutive (left) and bifurcation (right) manifold of minichannel heat exchanger [23].

seen in trees, cracks in the dry ground, blood circulation system and lungs [24]. Here, main fluid stream is divided into two streams. Each stream is then further subdivided into two more till the number of divisions matches the number of channels. In the end they are merging till main fluid stream creation. In [25] comparison of several manifolds was made and it is found out that the bifurcation structure gives much better distribution, which resulted in very uniform temperature field over the heating surface.

There are several papers [26-30] that introduce analytical models which describe the flow distribution in manifolds. One that could be used to predict the velocity distribution, flow distribution, and pressure drop was shown in [26]:

$$
\frac{1}{\rho} \frac{d P}{d Z}+\frac{f}{2 D} W^{2}+(2-\beta) W \frac{d W}{d Z}=0 .
$$

This model contain the mass balance, momentum balance and utilized Bernoulli's equation and was prepared for macrochannel plate heat exchangers, however it is also applicable for micro- or mini- scale. The aim of many authors' projects is to elaborate a method that will allow to predict a single or two-phase flow distribution, pressure drops and heat transfer in a minichannel heat exchangers very precisely. Hence, many papers are focused on a numerical simulations as a predictive tool for flow distribution in parallel micro- or minichannels. Tuo and Hrnjak [31] modeled a microchannel evaporator with a consideration that every single microchannel is a unique flow path and that various pressure drops along each flow path must add up to the same overall pressure drop. Comparison of predicted and measured evaporator cooling capacity shows that nearly $88 \%$ of the data points are predicted within $\pm 5 \%$ deviation from the experimental re- 
sults. Comparison of predicted and measured pressure drop shows that nearly $92 \%$ of the data points are predicted within $\pm 20 \%$ deviation from the experimental results. New microchannel heat exchanger cosimulation approach was proposed by [32]. It combines a detailed header simulation based on commercial computational fluid dynamics (CFD) code (Fluent) and a robust effectiveness-based finite volume tube-side heat transfer and refrigerant flow modeling tool. Also in [33] simulation has been done to predict the flow distribution in the inlet header of plate-fin heat exchangers. Authors found out that flow maldistribution is strongly pronounced at greater Reynolds number and two modified headers with a twostage-distributing structure were recommended to improve the distribution. Nielsen et al. [34] proposed a numerical method to quantify the heat transfer degradation associated with the non-uniform flow channel thickness in microchannel heat exchanger. Lalot et al. [35] suggested analytical expression that allows to approximate fluid velocity field in microchannel heat exchanger. Authors compared a computed results with experiments and obtained a good estimation.

Many authors conducted experiments that have allowed to indicate parameters that affect flow distribution. Minqiang et al. [36] carried out CFD-based studies of maldistribution in 20 parallel channels. The variable parameters were manifold's dimensions (length, magnitude and position of inlet/outlet) and microchannel's dimensions (length, width, and depth). All this parameters have influence on maldistribution. Kumaraguruparan et al. [37] conducted in numerical and experimental research of flow maldistribution in parallel microchannels in U-type configuration. These studies have shown the presence of flow separation, backflows and vortex at the inlet. These phenomena cause maldistribution but the increase of viscosity of the fluid reduces these effects. Another research on the influence of flow maldistribution on temperature and hot spot formation in 10 parallel channels with various hydraulic diameter was carried out in [38]. Authors investigated and compared maldistribution on three channel flow configurations (U-, Z-, and I-type) and various heat flux generated. They found out that the smaller the diameter of channels, the smaller the maldistribution. Thus the temperature difference over the surface was also smaller. Other researchers [39] found out that the best distribution is obtained when the fluid enters the inlet header perpendicular to the length of the header. Moreover rectangular header shape gives lower maldistribution at high flow rate while trapezoidal and triangular header shape gives lower maldistri- 
bution at low flow rate. It is found that irrespectively of header shape or flow inlet configuration the flow becomes more uniform at higher flow rate.

Hydraulic characteristics of minichannel heat exchangers are the prerequisites for using them in any thermal applications. Knowledge of pressure drop at different flow rates is essential to be able to predict the pumping power. Current studies are scheduled to check the potential of minichannel heat exchanger as an evaporator in a perspective design of the solar thermosiphon installation. For that reason authors measured pressure drop in single phase flow at low volume flow rates, typical which occurs in thermosiphon installations and visualized the flow distribution in minichannel heat exchanger.

\section{$2 \quad$ Experimental setup}

Authors used four model plate heat exchangers with a set of parallel minichannels made of brass. The measuring section contained 51 channels (connected by common inlet and outlet trapezoidal manifold) of $40 \mathrm{~mm}$ length with rectangular cross-section of different dimensions, i.e., width $\mathrm{x}$ depth were respectively: $1 \mathrm{~mm} \times 0.3 \mathrm{~mm} / 0.4 \mathrm{~mm} / 0.5 \mathrm{~mm} / 0.6 \mathrm{~mm}$ (corresponding to hydraulic diameter of $461 \mu \mathrm{m}, 574 \mu \mathrm{m}, 667 \mu \mathrm{m}$, and $750 \mu \mathrm{m}$, respectively). The model geometry was shown in Fig. 2.

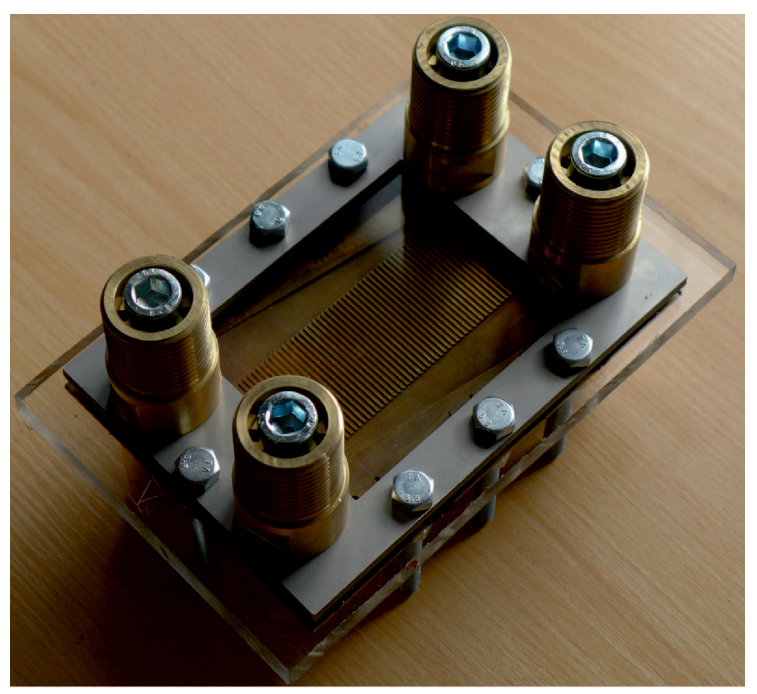

Figure 2: Model minichannel plate heat exchanger. 
In order to observe the working fluid, the section was covered with $10 \mathrm{~mm}$ acrylic glass sheet. Authors were filling empty heat exchanger with water at various mass flow rates $(0.83-8.33 \mathrm{~g} / \mathrm{s})$, and recorded the entire section with Panasonic Lumix LX7 camera. This camera allows to record sequences of records at $1920 \times 1080$ resolution. Other parameters of the camera were: shutter speed 50-500 $\mu$ s, frame rate $50 \mathrm{fps}$, focal length (small pic. eqiv.) $=70 \mathrm{~mm}$. The traditional $1000 \mathrm{~W}$ halogen lamp was used for illumination of the measuring section. At the same time, the pressure drop at the heat exchanger was measured using an ATM.1ST electronic pressure transmitter with a measuring range of $0-5 \mathrm{kPa}$. It worked with the National Instruments SCXI-1600 measuring interface and LabView environment. In addition, the test rig has been equipped with a valve and installation for removing water from the test section before, every measuring series were accomplished, using compressed air. This allowed to prepare the characteristics of pressure drop and to observe the flowing fluid and possible flow maldistribution in the individual channels.

Selection of the minichannel heat exchangers geometry results from authors' long-standing experience [40-42] of investigations in minichannels with various aspects, ranging from single phase to two-phase flows.

\section{Results and discussion}

Authors obtained a repeatability of results and stated that air content in the flowing medium has no influence on the flow profile. That is clearly seen in Fig. 3. The shape of flow profile is caused by the geometry of test section, i.e., shape and dimensions of inlet and outlet manifold and cross-section of minichannels itself. Fig. 3 shows also a phenomenon of flow maldistribution. The heads of flow in every single channel are not collinear and have different velocity, i.e., they have filled channels at different time. It was observed that the flow maldistribution depends on mass flow rate (higher flow rate, more uniform distribution) and hydraulic diameter of channels (lower hydraulic diameter, more uniform distribution). It corresponds with other authors' observations, that is to reduce the flow maldistribution, the effect of inertia should be reduced and the effect of viscosity should be increased. Hence, larger pressure drop should be in the channels and lower in inlet and outlet manifold [31,36,37,39].

Most of studies are made in the steady state, e.g., at constant flow rate, at constant temperature or constant heat flux. However, every installation 


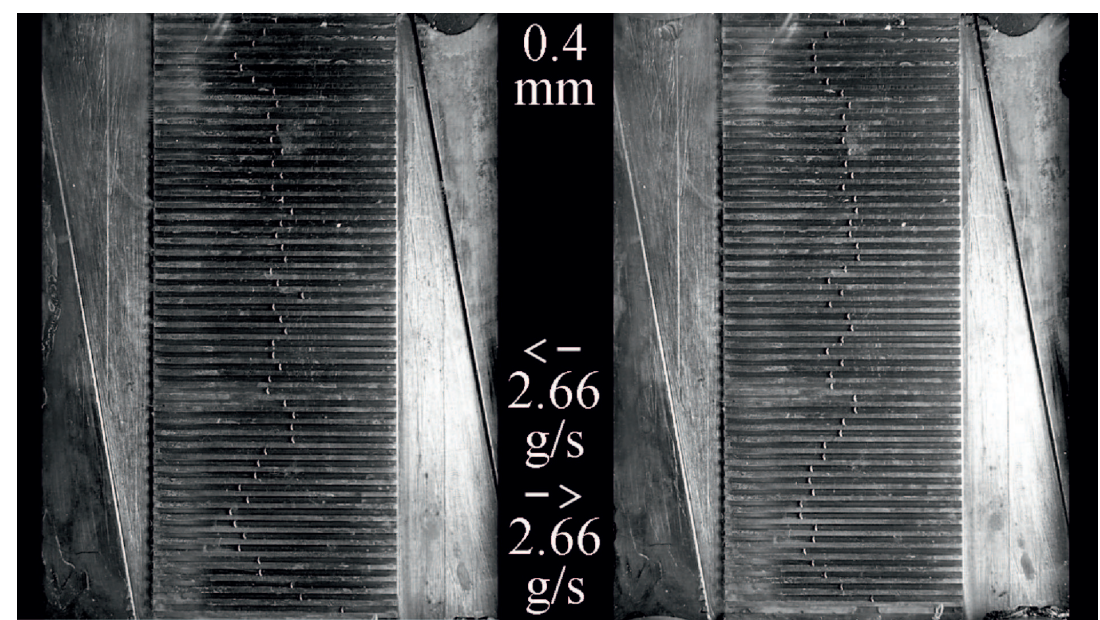

Figure 3: Comparison of flow profiles for two different measurement series concerning the same minichannel depth $(0.4 \mathrm{~mm})$ at equal flow rates of $2.66 \mathrm{~g} / \mathrm{s}$. Aerated water (left), degassed water (right).

has to be started up at least once but in many cases the moment when the working fluid is starting to flow occurs periodically. Current studies show the moment when fluid is starting to flow and enters the model minichannel heat exchanger. This situation is common in solar thermosiphon installation, where fluid enters the evaporator due to density differences of hot and cold medium as the solar energy is transferred. This approach allowed to observe the phenomena of channel blockage, which will be analysed in the paper.

In Fig. 4 the test section (geometry with the hydraulic diameter of $750 \mu \mathrm{m})$ when the head of flow reached the outlet at different flow rates was presented. The white lines represent blocked channels which were not filled with water entirely. Black lines represent blocked channels filled with water but blocked with the air bubble in outlet manifold. The working fluid does not flow in the channels that are not filled with water entirely, so the heat exchanger works unevenly. Uneven temperature distribution over the surface and lower heat exchanger's efficiency can be observed due to this situation. It was seen that more minichannels are inactive at low flow rates. The amount of inactive channels at the lowest flow rate $(1 \mathrm{~g} / \mathrm{s})$ is 16 and for $3.5 \mathrm{~g} / \mathrm{s}, 6.16 \mathrm{~g} / \mathrm{s}$, and $8.16 \mathrm{~g} / \mathrm{s}$ is getting smaller $(7,3$, and 0 , respectively). It is clearly shown that it low flow rates should be avoided. 

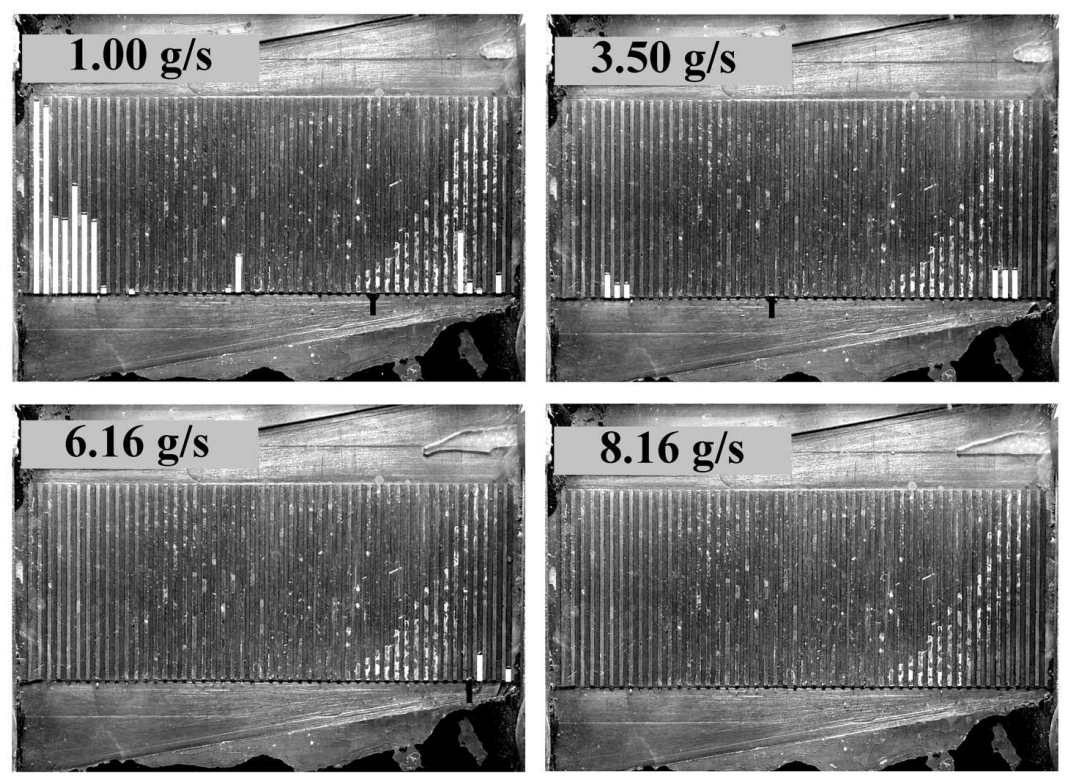

Figure 4: View of test section with blocked channels at different flow rates in the same geometry (minichannel depth of $0.6 \mathrm{~mm}$ ).

In Fig. 5 was presented the test section in similar situation as before but this time, the depth of the channel is a varying parameter and the flow rate in every case is the same and equals $1.83 \mathrm{~g} / \mathrm{s}$. It is seen that bigger hydraulic diameter of channels causes a bigger amount of the inactive channels. This amount rises from 4 inactive channels for the depth of minichannels' equal to $0.3 \mathrm{~mm}$ to 16 inactive channels for $0.6 \mathrm{~mm}$ minichannels' depth. For $0.4 \mathrm{~mm}$ and $0.5 \mathrm{~mm}$ depth amount of inactive channels are 7 and 10, respectively. It can be deduced that channels are blocked with recurrent mechanism that is strictly connected with flow maldistribution. For every geometry, the critical value of flow rate below which the maldistribution and channel blockage are severe, can be also distinguished. These issues will be the subject of wider research and separate publication.

Total pressure drop, which contains of pressure drop in inlet manifold, 51 parallel minichannels and outlet manifold was also measured. It is shown in Fig. 6. Values in Fig. 6 correspond to pressure drops in single minichannel plate itself, without hydraulic resistance in valves at the inlet and outlet. Pressure drop as a function of flow rate, as expected, increase as the flow rate increases, and increase as the hydraulic diameter of channels decreases. 

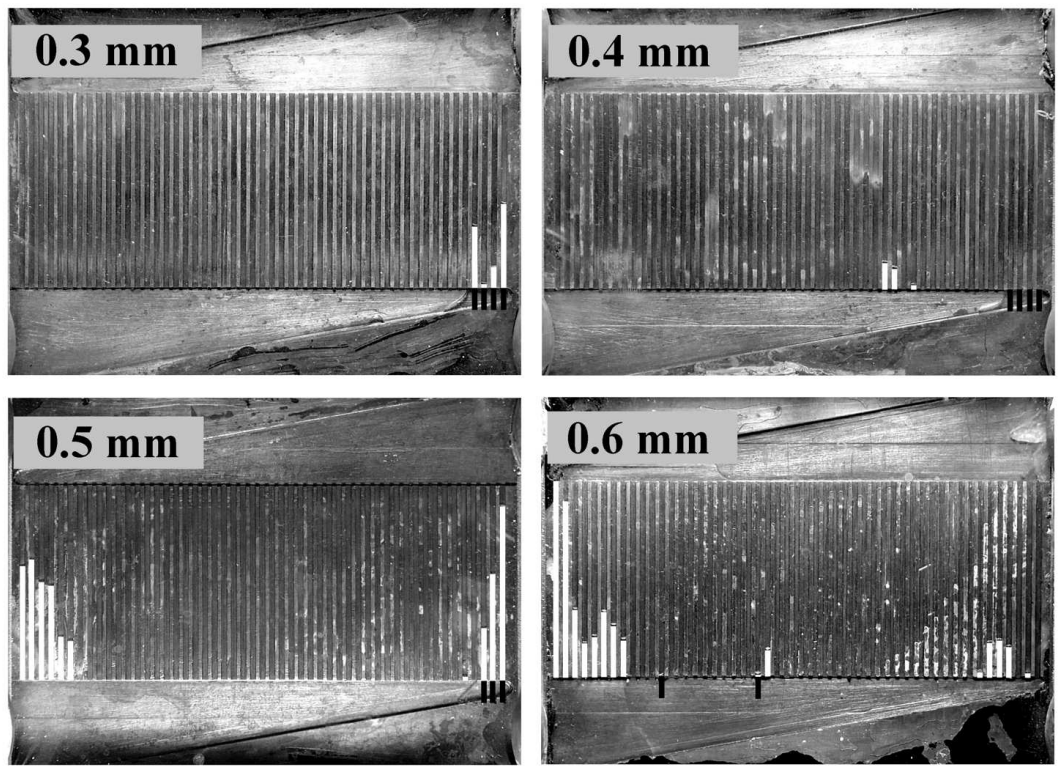

Figure 5: View of test section with blocked channels in different geometries (minichannel depths of $0.3 \mathrm{~mm}-0.6 \mathrm{~mm}$ ) at the same flow rate of $1.83 \mathrm{~g} / \mathrm{s}$.

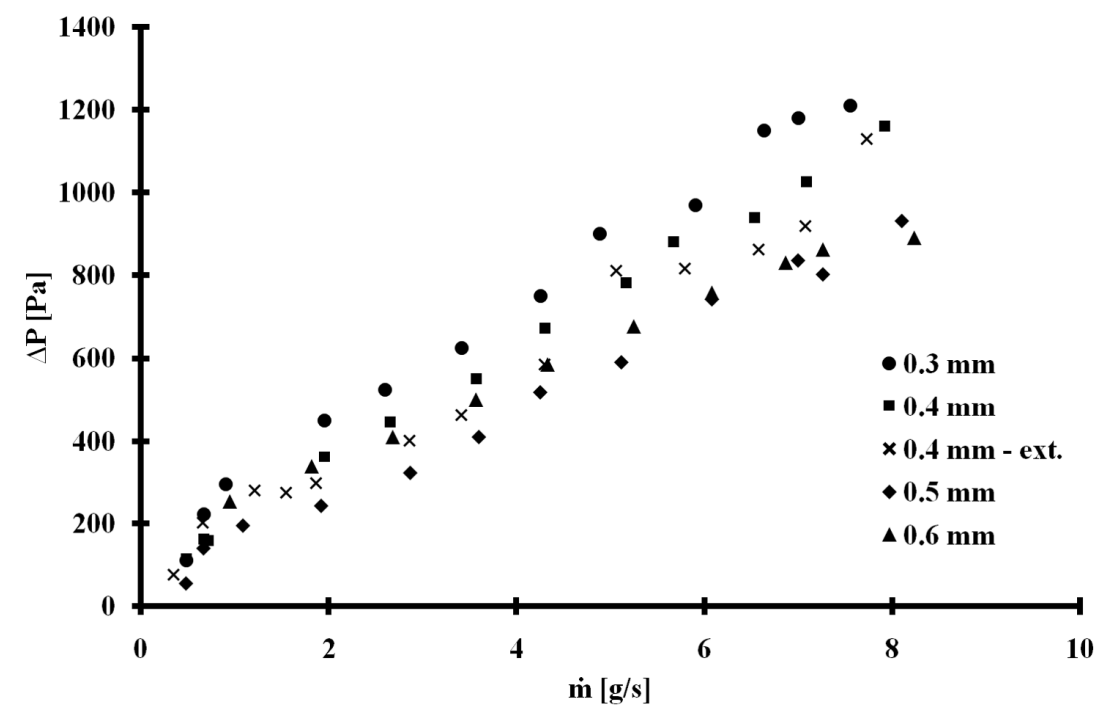

Figure 6: Pressure drop as a function of mass flow rate for various minichannels depth. 
In current studies value of pressure drop does not exceed $1250 \mathrm{~Pa}$, but worth remembering is the fact that this is a model of the heat exchanger with single plate and the real heat exchanger with minichannel plates should contain a number of them.

Authors made also pressure drop profiles as a function of the filling time of the section. These curves are reproducible and characteristic, which are related to the broader characteristics of the flow phenomena in the section. These issues will be the subject of wider research and separate publication.

\section{Conclusions}

Hydrodynamic studies in minichannel plate heat exchanger were made. Authors measured pressure drops in plate heat exchanger which contains of 51 parallel minichannels with rectangular cross-section of various hydraulic diameter $(461 \mu \mathrm{m}, 574 \mu \mathrm{m}, 667 \mu \mathrm{m}$, and $750 \mu \mathrm{m})$ connected by trapezoidal inlet and outlet manifold. Current studies were preliminary researches to check the potential of minichannel heat exchanger as an evaporator in solar thermosiphon installation. The single phase flow visualization at the moment of filling the model heat exchanger allowed to observe the flow maldistribution and the channels blockage phenomenon. Authors noticed the dependency of mass flow rate and channels' cross-section dimensions on maldistribution and blockage mechanism.

Due to the critical flow rate below which the deterioration of the work occurs and the parabolic nature of the pressure drop curve, there is a narrow range of flow at which model geometries can work optimally. It is a range in the order of $5 \mathrm{~g} / \mathrm{s}$ to $8.33 \mathrm{~g} / \mathrm{s}$. In this range the pressure drops are in range of $600-1250 \mathrm{~Pa}$, depending on the hydraulic diameter of channels. These values seem to be appropriate for the intended uses of the assumed geometry in a solar thermosiphon installation.

Acknowledgements The work presented in the paper was funded from the National Science Centre research project No. 2015/19/D/ST8/03201 in years 2016-2019.

Received 21 January 2017 


\section{References}

[1] TUCKERMAN D.B.: Pease RFW High-performance heat sinking for VLSI. IEEE Electr. Device Lett 2(1981), 5, 126-129. DOI: 10.1109/EDL.1981.253672.

[2] Teng J.: Fluid Dynamics in Microchannels. Intechopen 2012, 403-436. DOI: 10.1002/97835276314453.

[3] Mehendale S.S., Jacobi A.M., Shah R.K.: Fluid flow and heat transfer at micro- and meso-scales with application to heat exchanger design. Appl. Mech. Rev. 53(2000), 7, 175-193.

[4] Kandlikar S.G., Grande W.J.: Evolution of microchannel flow passagesthermohydraulic performance and fabrication technology. Heat Tran. Eng. 24(2003), 1, 3-17. DOI: 10.1080/014576303040405.

[5] Ornatskit A.P., Vinyarski L.S.: Heat transfer crisis in a forced flow of underheated water in small-bore tubes. Teplofiz. Vysok. Temp. 3(1965), 441-451.

[6] Mudawar I.A., El-Masri M.A. Wu C.S., Ausman-Mudawwar J.R.: Boiling heat transfer and critical heat flux in high-speed rotating liquid films. Int. J. Heat Mass Tran. 28(1985), 4, 795-806. DOI: 10.1016/0017-9310(85)90230-3

[7] Sturgis J.C., Mudawar I.: Assessment of CHF enhancement mechanisms in a curved, rectangular channel subjected to concave heating. J. Heat Transfer 121(1999), 2, 394-404.

[8] Hall D.D., Mudawar I.: Ultra-high critical heat flux (CHF) for subcooled water flow boiling? II: high-CHF database and design equations. Int. J. Heat Mass Transf. 42(1999), 8, 1429-1456. DOI: 10.1016/S0017-9310(98)00242-7

[9] Mikielewicz D., Mikielewicz J.: A thermodynamic criterion for selection of working fluid for subcritical and supercritical domestic micro CHP. Appl. Therm. Eng. 30(2010), 16, 2357-2362. DOI: 10.1016/j.applthermaleng.2010.05.035.

[10] Mudawar I: Assessment of high-heat-flux thermal management schemes. IEEE Trans. Comp. Pack. Technol. 24(2001), 2, 122-141. DOI: 10.1109/6144.926375.

[11] Mudawar I. Two-phase microchannel heat sinks: theory, applications, and limitations. J. Electron Packag. 133(2011), 4, 41002-41031.

[12] Jimenez P.E., Mudawar I.: A multi-kilowatt immersion-cooled standard electronic clamshell module for future aircraft avionics. J Electron Packag. 116(1994), 3, 220229 .

[13] LaClair T.J., MUdaWAR I.: Thermal transients in a capillary evaporator prior to the initiation of boiling. Int. J. Heat Mass Tran. 43(2000), 21, 3937-3952. DOI: 10.1016/S0017-9310(00)00042-9

[14] Reddy S.R., Ebadian M.A., Lin C-X.: A review of PVT systems: thermal management and efficiency with single phase cooling. Int. J. Heat Mass Tran. 91(2015), 861-871. DOI: 10.1016/j.ijheatmasstransfer.2015.07.134.

[15] Mudawar I., Bharathan D., Kelly K., Narumanchi S.: Two-phase spray cooling of hybrid vehicle electronics. IEEE Trans. Components Packag. Technol. 32(2009), 2, 501-512. DOI: 10.1109/TCAPT.2008.2006907. 
[16] JY R., LY L., XS D. et al.: Numerical investigations on characteristics of methane catalytic combustion in micro-channels with a concave or convex wall cavity. Energy Convers Manag 97(2015), 188-195. DOI: 10.1016/j.enconman.2015.03.058.

[17] Berthier J., Brakke K.A., Furlani E.P. et al: Whole blood spontaneous capillary flow in narrow V-groove microchannels. Sensors Actuators, B Chem 206(2015), 258-267. DOI: 10.1016/j.snb.2014.09.040.

[18] Kim S.M., Mudawar I.: Review of databases and predictive methods for heat transfer in condensing and boiling mini/micro-channel flows. Int. J. Heat Mass Tran. 77(2014), 627-652. DOI: 10.1016/j.ijheatmasstransfer.2014.05.036.

[19] KANDLIKAR S.G.: High flux heat removal with microchannels - A roadmap of challenges and opportunities. Heat Transfer Eng. 26(2005), 8, 5-14. DOI: 10.1080/01457630591003655.

[20] Mueller A.C., Chiou J.P.: Review of various types of flow maldistribution in heat exchangers. Heat Tranfer Eng. 9(1988),36-50. DOI: 10.1080/01457638808939664.

[21] Wen J., Li Y.: Study of flow distribution and its improvement on the header of plate-fin heat exchanger. Cryogenics (Guildf) 44(2004), 11, 823-831. DOI: 10.1016/j.cryogenics.2004.04.009.

[22] Wang J.: Theory of flow distribution in manifolds. Chem. Eng. J. 168(2011), 3, 1331-1345. DOI: 10.1016/j.cej.2011.02.050.

[23] Amador C., Gavrillidis A., Angeli P.: Flow distribution in different microreactor scale-out geometries and the effect of manufacturing tolerances and channel blockage. Chem. Eng. J. 101(2004), 1-3, 379-390. DOI: 10.1016/j.cej.2003.11.031.

[24] Bejan A., ERRERA M.R.: Deterministic tree networks for fluid flow: geometry for minimal flow resistance between a volume and one point. Fractals 5(1997), 4, 685-695. DOI: 10.1142/S0218348X97000553.

[25] Ramos-Alvarado B., Li P., Liu H., Hernandez-Guerrero A.: CFD study of liquid-cooled heat sinks with microchannel flow field configurations for electronics, fuel cells, and concentrated solar cells. Appl. Therm. Eng. 31(2011), 14-15, 24942507. DOI: 10.1016/j.applthermaleng.2011.04.015.

[26] Bassiouny M.K., Martin H.: Flow distribution and pressure drop in plate heat exchangers-I U-type arrangement. Chem. Eng. Sci. 39(1984), 4, 693-700. DOI: 10.1016/0009-2509(84)80176-1.

[27] Bassiouny M.K., Martin H.: Flow distribution and pressure drop in plate heat exchangers-II Z-type arrangement. Chem. Eng. Sci. 39(1984), 4, 701-704. DOI: 10.1016/0009-2509(84)80177-3.

[28] Bajura R.A.: A model for flow distribution in manifolds. J. Eng. Power 93(1971), $1,7-12$.

[29] Acrivos A., BABCOCK B.D., Pigford R.L.: Flow distributions in manifolds. Chem. Eng. Sci. 10(1959), 1-2, 112-124. DOI: 10.1016/0009-2509(59)80030-0.

[30] Wang J., Gao Z., Gan G., Wu D.: Analytical solution of flow coefficients for a uniformly distributed porous channel. Chem. Eng. J. 84(2001), 1, 1-6. DOI: 10.1016/S1385-8947(00)00263-1. 
[31] Tuo H., Hrnjak P.: Effect of the header pressure drop induced flow maldistribution on the microchannel evaporator performance. Int. J. Refrig. 36(2013), 8, 2176-2186. DOI: 10.1016/j.ijrefrig.2013.06.002.

[32] Huang L., Lee M.S., Saleh K. et al.: A computational fluid dynamics and effectiveness-NTU based co-simulation approach for flow mal-distribution analysis in microchannel heat exchanger headers. Appl. Therm. Eng. 65(2014), 1-2, 447457. DOI: 10.1016/j.applthermaleng.2014.01.046.

[33] Zhang Z., Li Y.: CFD simulation on inlet configuration of plate-fin heat exchangers. Cryogenics (Guildf) 43(2003), 12, 673-678. DOI: 10.1016/S0011-2275(03)001796.

[34] Nielsen K.K., Engelbrecht K., Christensen D.V. et al.: Degradation of the performance of microchannel heat exchangers due to flow maldistribution. Appl. Therm. Eng. 40(2012), 236-247. DOI: 10.1016/j.applthermaleng.2012.02.019.

[35] Lalot S., Florent P., Lang S.K., Bergles A.E.: Flow maldistribution in heat exchangers. Appl. Therm. Eng. 19(1999), 8, 847-863. DOI: 10.1016/S13594311(98)00090-8.

[36] Minqiang P., Dehuai Z., Yong T., Dongqing C.: CFD-based study of velocity distribution among multiple parallel microchannels. J. Comput. 4(2009), 11, 11331138. DOI: $10.4304 /$ jcp.4.11.1133-1138.

[37] Kumaraguruparan G., Kumaran R.M., Sornakumar T., Sundararajan T.: A numerical and experimental investigation of flow maldistribution in a microchannel heat sink. Int. Commun. Heat Mass Tran. 38(2011), 10, 1349-1353. DOI: 10.1016/j.icheatmasstransfer.2011.08.020.

[38] Manoj Siva V., Pattamatta A., Das S.K.: Effect of flow maldistribution on the thermal performance of parallel microchannel cooling systems. Int. J. Heat Mass Tran. 73(2014), 424-428. DOI: 10.1016/j.ijheatmasstransfer.2014.02.017.

[39] Anbumeenakshi C., Thansekhar M.R.: Experimental investigation of header shape and inlet configuration on flow maldistribution in microchannel. Exp. Therm. Fluid Sci. 75(2016), 156-161. DOI: 10.1016/j.expthermflusci.2016.02.004.

[40] Mikielewicz D., Klugmann M.: A study of flow boiling heat transfer in minichannels. Arch Thermodyn. 29(2008), 2, 73-84.

[41] Mikielewicz D., Klugmann M., Wajs J.: Flow boiling intensification in minichannels by means of mechanical flow turbulising inserts. Int. J. Therm. Sci. 65(2013), 79-91. DOI: 10.1016/j.ijthermalsci.2012.10.002.

[42] Mikielewicz D., Wajs J., Andrzejczyk R., Klugmann M.: Pressure drop of HFE7000 and HFE7100 during flow condensation in minichannels. Int J. Refrig. 68(2016), 226-241. DOI: 10.1016/j.ijrefrig.2016.03.005. 